\title{
Pengelolaan Produk Kuliner Sebagai Oleh-Oleh Khas Kabupaten Gunung Kidul
}

\author{
Anggi Martiningtyas Januwati Saputri*, Yulia Arisnani Widyaningsih \\ Universitas Negeri Malang, Jl. Semarang No. 5 Malang, Jawa Timur, Indonesia \\ Universitas Gadjah Mada, Jl. Teknika Utara, Pogung, Sinduadi, Sleman, Yogyakarta, Indonesia \\ *Penulis korespondensi, Surel: anggi.saputri.ft@um.ac.id
}

Paper received: 06-04-2021; revised: 20-04-2021; accepted: 24-04-2021

\begin{abstract}
Abstrak
Salah satu kabupaten di Daerah Istimewa Yogyakarta yang pesat akan perkembangan pariwisatanya adalah Gunung Kidul. Banyak sekali wahana yang disajikan di Gunung Kidul, baik wisata alam, wisata buatan maupun wisata kuliner. Obyek Daya Tarik yang ada di Gunung Kidul meliputi wisata air (pantai, telaga), wisata alam (goa, pegunungan) dan desa wisata. Selain obyek wisata tersebut, wisata kuliner merupakan salah satu wisata yang sangat digemari oleh para wisatawan yang berkunjung ke Gunung Kidul. Ada beberapa makanan khas Gunung Kidul yang menjadi icon daerah, yaitu nasi merah atau warga Gunung Kidul menyebutnya sego abang, olahan ikan segar, gathot, tiwul, peyek jingkeng, walang goreng dan walang bacem. Masyarakat membuat produk kuliner yang lebih variasi, agar wisatawan dapat menikmati citarasa yang baru. Dengan cara ini masyarakat mendapat peluang usaha di bidang kuliner. Kuliner yang disajikan di Gunung Kidul menjadi daya tarik wisatawan sendiri, dengan demikian usaha kuliner khususnya oleh-oleh khas Gunung Kidul dapat berkembang pesat. Metode yang dilakukan dalam penelitian ini adalah metode kualitatif. Rumah makan Pari Gogo dan toko oleh-oleh "Yu Tum" merupakan lokasi penelitian. Hasil dari penelitian ini menunjukkan bahwa perkembangan kuliner di Gunung kidul sangat variatif, hal ini dapat dilihat dari banyaknya produk inovasi baru yang dibuat dari bahan dasar yang ada di Gunung Kidul. Makanan dibuat menjadi lebih modern dan lebih tinggi harganya.
\end{abstract}

Kata kunci: produk kuliner; oleh-oleh; kabupaten Gunung Kidul

\section{Pendahuluan}

Saat ini pariwisata di Indonesia sangat maju pesat, hal ini dapat dilihat dari minat masyarakat baik lokal maupun mancanegara gemar melakukan perjalanan wisata. Salah satu hal yang keberadaannya sangat berpengaruh terhadap perkembangan suatu daerah adalah pariwisata. Tujuan dari wisatawan melakukan perjalanan wisata adalah untuk memuaskan hasrat, mengurangi stress dan kepenatan. Dengan melakukan perjalanan wisata, wisatawan akan menjadi lebih fresh dan tidak stress. Salah satu jenis wisata yang berkembang pesat adalah wisata kuliner, yang mana wisata kuliner merupakan wisata yang sangat diminati oleh wisatawan. Banyak wisatawan yang mengunjungi suatu daerah hanya karena kuliner yang disajikan. Dengan demikian wisata kuliner menjadi peluang besar bagi suatu daerah destinasi wisata. Wisatawan tidak akan segan mengeluarkan uang untuk menikmati kuliner khas suatu daerah. Sekarang ini gaya hidup manusia telah berubah, wisatawan mengkonsumsi kuliner tidak hanya untuk mengenyangkan perut, tetapi wisatawan juga ingin menikmati suasana yang nyaman. Selain itu, cara melayani wisatawan dan penyajian makananpun menjadi salah satu faktor yang membuat wisatawan puas dalam menikmati hidangan yang disajikan.

Kabupaten Gunung Kidul dikenal sebagai salah satu destinasi favorit tujuan wisatawan lokal maupun asing saat berkunjung ke Yogyakarta. Dari kelima kabupaten yang ada di Daerah Istimewa Yogyakarta, kabupaten Gunung Kidul ini merupakan daerah yang subur dan hijau. 
Dulu Gunung Kidul merupakan perbukitan yang tandus dan selalu mengalami kekeringan. Akan tetapi sekarang Gunung Kidul merupakan tempat yang hijau, segar dan memiliki banyak potensi wisata.

Destinasi wisata yang ada di Gunung Kidul sangat banyak, mulai dari alami hingga buatan. Pantai dan gua merupakan wisata andalan dari kabupaten Gunung Kidul. Selain itu di Gunung Kidul juga terdapat banyak desa wisata, di antaranya adalah Garotan, Mojo, Bobung, Nglangeran, Bejiharjo, Umbulrejo, dll. Adapun fasilitas di desa wisata tersebut meliputi outbound, susur gua, susur sungai, membajak sawah, dan menikmati makanan khas dari Gunung Kidul. Dengan adanya desa wisata ini makanan lokal lebih mudah dikenal oleh masyarakat luas. Selain atraksi wisata tersebut, restoran, rumah makan, café dan toko pusat oleh-oleh juga merupakan aspek yang sangat penting dalam kemajuan industri pariwisata. Restoran/rumah makan merupakan suatu tempat yang diorganisasikan secara komersial, yang mana di dalamnya menjual makanan dan pelayanan. Tujuan operasional restoran adalah untuk melakukan bisnis, mencari keuntungan dan melayani tamu dengan sepenuh hati agar tamu merasa puas menikmati makanan dan minuman di restoran kita. Berbagai jenis makanan maupun minuman disajikan dan di jual dengan semenarik mungkin, hal ini bertujuan agar wisatawan tertarik untuk menikmati makanan dan minumakn yang di jual.

Saat ini Kabupaten Gunung Kidul menjadi daerah tujuan wisata para wisatawan lokal maupun mancanegara. Sama halnya dengan kabupaten lainnya, saat ini kabupaten Gunung Kidul terus diperbaharui dengan tujuan agar terlihat lebih bagus. Berbagai tempat wisata didesain sesuai dengan trend masa kini. Bisnis kuliner sangat berpengaruh pada banyaknya wisatawan yang berkunjung ke obyek wisata yang ada di Gunung Kidul. Setiap produsen makanan berlomba-lomba untuk mengkreasikan olahan khas Kabupaten Gunung Kidul, seperti sego abang, belalang goreng, belalang bacem, belalang pedas manis, gathot, thiwul, aneka olahan ikan, peyek jingkeng dan olahan rumput laut. Beberapa contoh masakan lokal tersebut menjadi semacam ikon daerah Gunung Kidul. Maka tidak heran bahwa banyak wisatawan yang berkunjung ke Kabupaten Gunung Kidul khusus mencari makanan dan minuman khas Gunung Kidul. Yang menjdi daya tarik wisatawan untuk mengkonsumsi makanan khas gunung kidul adalah bahan baku yang segar, rasa yang khas, rempah yang lengkap dan tampilan yang sangat menggugah selera makan.

\section{Metode}

Metode yang digunakan dalam penelitian ini adalah metode deskriptif kualitatif yang mana peneliti merupakan instrument primer dalam teknik pengumpulan datanya, di antaranya dalah observasi, wawancara dan dokumentasi. Kabupaten Gunung Kidul tepatnya di Semanu dan Wonosari merupakan lokasi dalam penelitian ini, yang mana kabupaten Gunung Kidul merupakan daerah yang bercurah hujan rendah, dan menghasilkan tanaman padi merah, yang dikenal dengan sebutan pari abang gogo. Pari abang ini memliliki tekstur punel, rasa enak, dan mengandung gizi yang tinggi.

Di daerah Wonosari Gunung Kidul terdapat sebuah toko oleh-oleh makanan khas Gunung Kidul yang bernama "Yu Tum". Toko ini menjual oleh-oleh khas Gunung Kidul yaitu thiwul dan gathot. Sekarang ini gathot dan tiwul menjadi makanan yang dikenal di seluruh Indonesia. Makanan yang berasal dari singkong ini telah menjelma menjadi makanan yang memiliki harga jual tinggi. Gathot dan tiwul tidak dianggap makanan murahan lagi, karena telah diolah dan dikemas sebagus mungkin, sehingga wisatawan tertarik untuk membeli dan 
mengkonsumsi. Sumber data atau informan dalam penelitian ini meliputi pelaku usaha dan konsumen atau wisatawan yang membeli oleh-oleh kiliner khas Gunung Kidul. Data yang diperoleh diolah secara manual, dengan cara diidentifikasi, dipilah, dikelompokkan, dianalisis, dan hasilnya dilaporkan dalam artikel ini.

\section{Hasil dan Pembahasan}

Kabupaten gunung kidul merupakan kabupaten yang terdapat di daerah istimewa yogyakarta. Dahulu Gunung Kidul dikenal sebagai daerah yang tandus, gersang dan daerah yang kekurangan air. Akan tetapi sekarang terdapat peluang besar wisatawan untuk melakukan wisata di Gunung Kidul. Hal ini dikarenakan di daerah Gunnung Kidul memiliki beberapa hal yang sangat menarik wisatawan, baik dari segi keindahan yang dapat dilihat, kegiatan yang dapat dilakukan di Kabupaten Gunung Kidul, dan beberapa produk yang dapat dibeli di Gunung Kidul, salah satunya adalah produk makanan khas daerah Gunung Kidul. Gunung Kidul menyajikan hamparan laut yang luas, pegunungan, gua yang indah, pemandangan yang sangat bagus dan wisata kuliner yang sangat enak dan beraneka ragam. Keberadaan obyek wisata dan atraksi wisata di daerah Gunung Kidul sangat bermanfaat bagi masyarakat sekitar oyek wisata, karena masyarakat dapat membuaka usaha di daerah sekitar obyek wisata, seperti rental sepeda motor, rumah makan, toko oleh-oleh, persewaan alat berwisata/camping.

Kabupaten Gunung Kidul memiliki makanan khas yang sangat diminati oleh wisatawan, selain rasa yang khas kandungan dari makanan yang ada di Gunung Kidul juga sangat bagus untuk tubuh kita. Oleh-oleh dari Gunung Kidul juga sangat bervariasi. Wisatawan dapat membeli oleh-oleh dengan harga yang relatif terjangkau. Produk yang dijual di Gunung Kidul merupakan produk yang jarang sekali ditemui di daerah lain. Sego abang, gathot, tiwul, belalang Goreng merupakan beberapa makanan lokal yang menjadi ciri khas kabupaten Gunung Kidul. Makanan ini termasuk makanan lokal yang memiliki nilai jual yang tinggi. Bahan baku yang digunakan dalam pembuatan produk makanan khas Gunung Kidul merupakan hasil dari daerah itu sendiri. Bahan yang digunakan adalah bahan yang sangat murah, tetapi diolah menggunakan resep khusus, sehingga menjadikan makanan bernilai tinggi. Menurut Murtiningsih (wawancara, 28 November 2019" di mana-mana banyak dijual tiwul dan gathot, tapi rasa dari tiwul dan gathot dari Gunung Kidul sangat beda, tiwulnya enak, legit, dan rasanya pas, gurih dipadukan manis dari gula jawa yang ada di dalamnya, selain itu kemasannya juga sangat menarik, menggunakan besek, yang membuat tiwul dan gathot tidak mudah basi". Harga Oleh-oleh di toko Yu Tum relative terjangkau. Tabel 1 di bawah ini menyajikan harga makanan yang dijual di Toko Yu Tum.

Tabel 1. Daftar harga makanan di Toko Yu Tum

\begin{tabular}{llll}
\hline No & Nama Menu & Harga \\
\hline 1 & Thiwul Utuh & $\mathrm{Rp}$ & 20.000 \\
2 & Thiwul Setengah & $\mathrm{Rp}$ & 10.000 \\
3 & Thiwul Coblong & $\mathrm{Rp}$ & 18.000 \\
4 & Thiwul tumpeng & $\mathrm{Rp}$ & 50.000 \\
5 & Thiwul Srintil & $\mathrm{Rp}$ & 18.000 \\
6 & Thiwul rasa nangka setengah & $\mathrm{Rp}$ & 15.000 \\
7 & Thiwul rasa keju setengah & $\mathrm{Rp}$ & 18.000 \\
8 & Thiwul rasa coklat setengah & $\mathrm{Rp}$ & 15.000 \\
9 & Gathot Kecil & $\mathrm{Rp}$ & 8.000 \\
10 & Gathot Besar & $\mathrm{Rp}$ & 20.000 \\
\hline
\end{tabular}




\begin{tabular}{llll}
\hline No & Nama Menu & \multicolumn{2}{l}{ Harga } \\
\hline 11 & Gathot Thiwul Utuh & $\mathrm{Rp}$ & 20.000 \\
12 & Gathot Thiwul Setengah & $\mathrm{Rp}$ & 12.000 \\
13 & Gathot Thiwul Seperempat & $\mathrm{Rp}$ & 6.000 \\
14 & Gethuk goreng $1 / 4 \mathrm{~kg}$ & $\mathrm{Rp}$ & 8.000 \\
15 & Gethuk goreng $1 / 2 \mathrm{~kg}$ & $\mathrm{Rp}$ & 15.000 \\
16 & Gethuk goreng 1 kg & $\mathrm{Rp}$ & 30.000 \\
17 & Cake thiwul pisang & $\mathrm{Rp}$ & 20.000 \\
18 & Cake thiwul nangka & $\mathrm{Rp}$ & 20.000 \\
19 & Cake thiwul keju & $\mathrm{Rp}$ & 22.500 \\
20 & Thiwul instan & $\mathrm{Rp}$ & 15.000 \\
21 & Gathot instan & $\mathrm{Rp}$ & 15.000 \\
22 & Thiwul instan & $\mathrm{Rp}$ & 15.000 \\
23 & Paphilo & $\mathrm{Rp}$ & 12.000 \\
24 & Aneka camilan & $\mathrm{Rp}$ & $10.000-30.000$ \\
25 & Sego abang lengkap & $\mathrm{Rp}$ & $40.000-50.000$ \\
26 & Belalang goring (Toples) & $\mathrm{Rp}$ & 60.000 \\
27 & Belalang bacem (Toples) & $\mathrm{Rp}$ & 65.000 \\
28 & Aneka minuman & $\mathrm{Rp}$ & $4.000-10.000$ \\
\hline
\end{tabular}

Sumber : Olah data pribadi, 2019

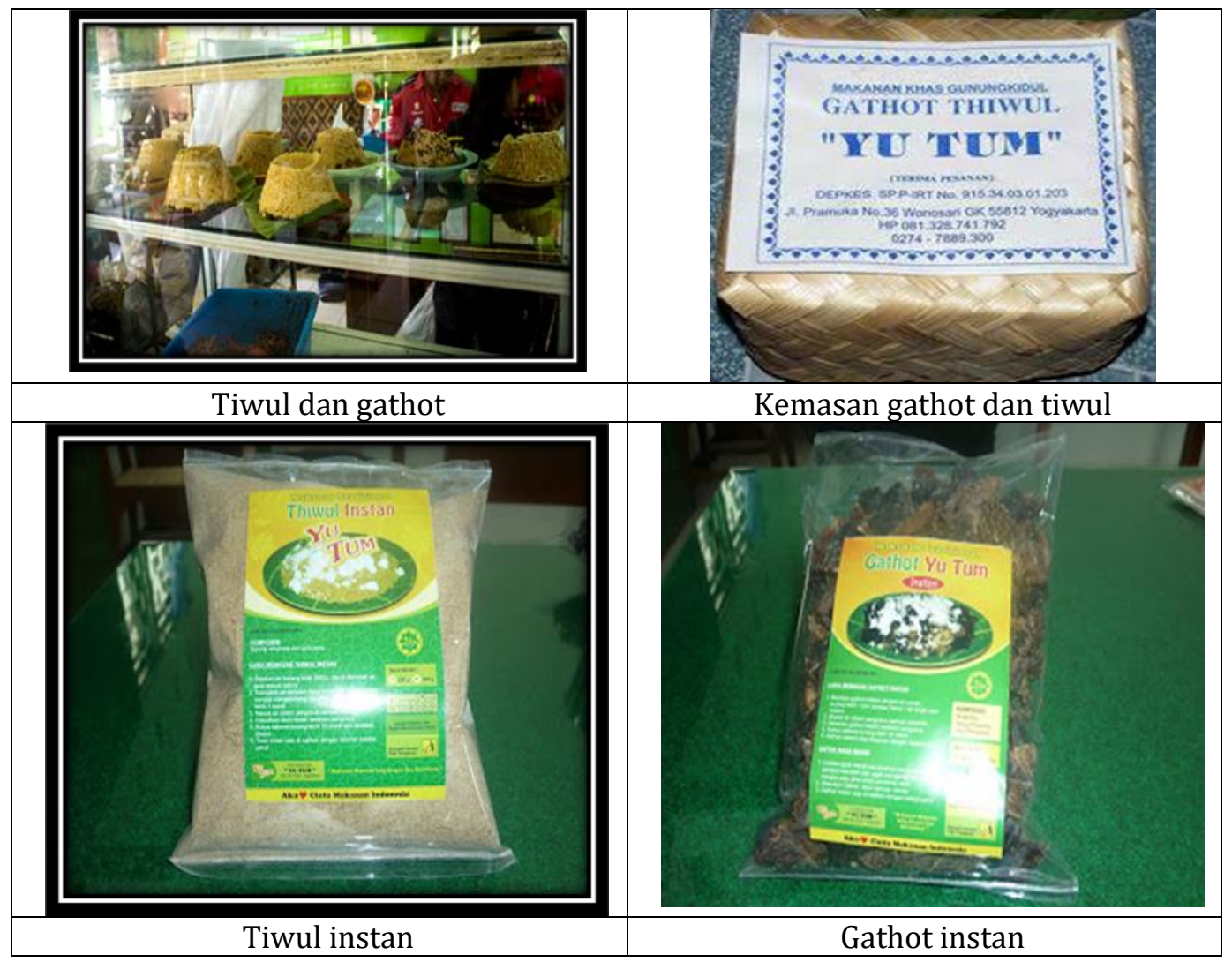

Gambar 2. Foto produk gathot dan tiwul Yu Tum (Sumber: Dokumentasi peneliti dan Google Image)

Selain gathot dan tiwul, sego abang juga menjadi salah satu makanan khas dari Gunung Kidul. Ciri khas dari sego abang adalah pelengkapnya yang menggunakan bumbu, rempah dan santan yang kental. Hal ini membuat rasa dari sego abang tersebut gurih. Sego abang disajikan 
beserta pelengkapnya memiliki karakteristik bumbu yang kental, manis, dan gurih. Pelengkap dari sego abang meliputi sayur Lombok ijo, daging sapi goreng, iso babat goreng, ikan wader goreng, ikan bakar/goreng, dan urap/ trancam. Isisan dari Sayur Lombok ijo ini adalah potongan cabe hijau dan tempe kedelai yang diberi bumbu bawang merah, bawang putih, jahe dan kemiri. Beras yang digunakan adalah padi gogo,yang tumbuh subur di gunung kidul.

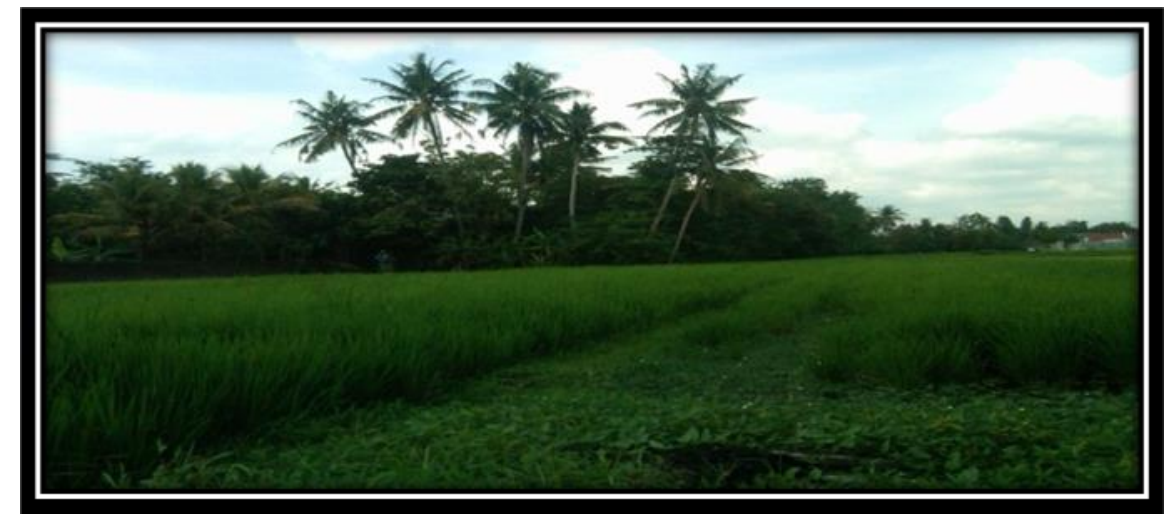

Gambar 3. Sawah yang menanam pari gogo beras merah di Gunung Kidul

Bahan dan bumbu lainnya seperti rempah, tempe didapat dari pasar Semanu, Gunung Kidul, sedangkan ikan segar diperoleh dari salah satu warga yang bekerja sebagai nelayan di Pantai Baron dan Sadeng Gunung Kidul "Setiap 3 hari sekali, saya menyetori ikan sekar sekitar $5 \mathrm{~kg}$ dan wader segar sekitar 20 kg" (Bapak Purnomo, 56 tahun). Dengan metode mendapatkan bahan baku seperti ini mereka mendapatkan bahan baku yang selalu segar dan bagus, sehingga harga jual sego abang dan pelengkap relatif murah. Selain harga, hal yang disukai dari wisatawan adalah dari segi pelayanannya. Pelayanan di rumah makan Pari Gogo masih sederhana, mulai dari tempat hingga pelayanannya. Penyajian sego abang dan pelengkapnya menggunakan cething dan piring makan yang diberi daun pisang sebagai alasnya, kemudian disantap diatas lincak dan lesehan. Wisatawan merasakan kenikmatan dan kenyamanan, karena wisatawan bebas memilih menu yang mereka suka. "Saya sangat senang di warung ini, karena menunya enak, tempatnya nyaman dan pelayannya cepat"(Andi 27 tahun)

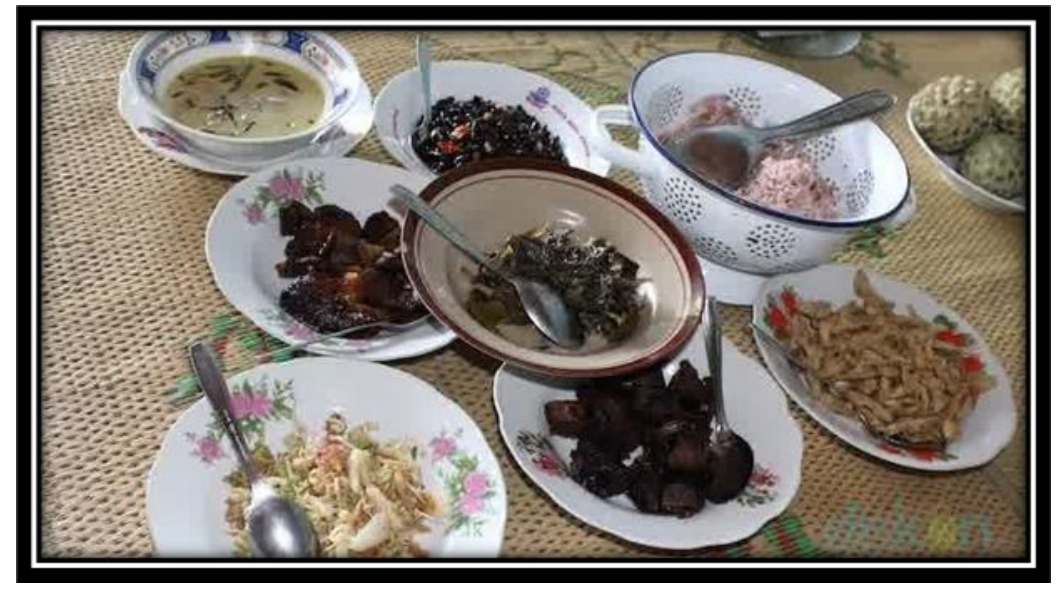

Gambar 4. Menu yang disajikan di rumah makan Pari Gogo 
Harga makanan di rumah makan Pari Gogo termasuk murah di banding dengan restoran lainnya. Tabel 2 menyajikan dafrtar harga yang dijual Rumah makan Pari Gogo.

Tabel 2. Daftar Harga Menu yang Dijual di Rumah Makan Pari Gogo

\begin{tabular}{|c|c|c|c|c|c|}
\hline No & Nama Menu & Jumlah & & Harga & Keterangan \\
\hline 1 & Sego abang & 1 cething & $\mathrm{Rp}$ & 20.000 & Untuk 3-4 orang \\
\hline 2 & Sayur Lombok ijo & 1 mangkok & $\mathrm{Rp}$ & 8.000 & Untuk 2 orang \\
\hline 3 & Daging sapi goreng/bacem & 1 piring & $\mathrm{Rp}$ & 50.000 & Untuk 3-4 orang \\
\hline 4 & Iso babat goreng, & 1 piring & $\mathrm{Rp}$ & 30.000 & Untuk 3-4 orang \\
\hline 5 & Wader goreng & 1 piring & $\mathrm{Rp}$ & 20.000 & Untuk 2 orang \\
\hline 6 & Ikan bakar/goring & 1 ekor & $\mathrm{Rp}$ & 30.000 & Untuk 2-3 orang \\
\hline 7 & Urap trancam & 1 piring & $\mathrm{Rp}$ & 10.000 & Untuk 2 orang \\
\hline 8 & Teh manis & 1 gelas & $\mathrm{Rp}$ & 4.000 & \\
\hline 9 & Jeruk manis & 1 gelas & $\mathrm{Rp}$ & 5.000 & \\
\hline 10 & Es degan & Utuh & $\mathrm{Rp}$ & 10.000 & Utuh \\
\hline
\end{tabular}

Sumber : Olah data pribadi, 2019

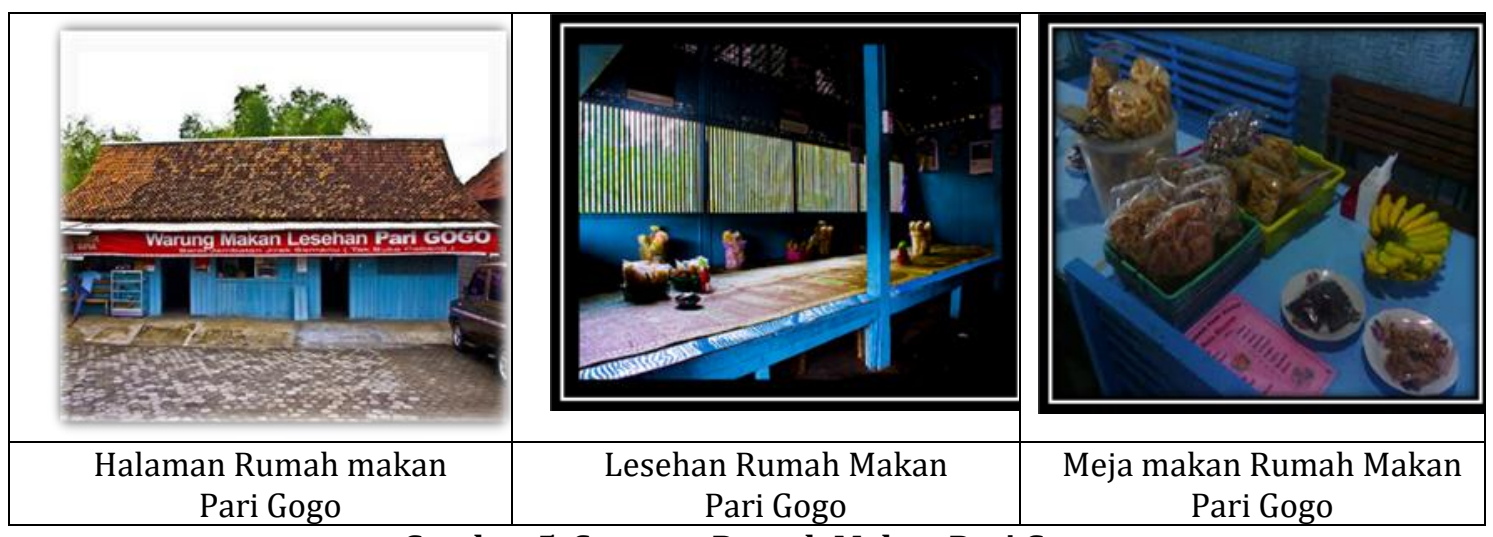

Gambar 5. Suasana Rumah Makan Pari Gogo.

\section{Simpulan}

Pada Bab sebelumnya telah diuraikan hasil penelitian dan pembahasan, yaitu: (1) Gunung Kidul merupakan daerah Tujuan Wisata, baik wisatawan domestic maupun wisatawan mancanegara, dengan adanya wisatawan yang datang ke Kabupaten Gunung kidul maka masyarakat juga mendapat keuntungan salah satuanya adalah masayakat dapat menjual kuliner khas Gunung Kidul. (2) Wisatawan yang berwisata di Kabupaten Gunung Kidul sangat mempengaruhi bisnis kuliner yang ada di Gunung Kidul(3)Kuliner yang terkenal dan dapat dijadikan oleh dari Gunung Kidul meliputi aneka olahan gathot, aneka olahan tiwul, sego abafng dan pelengkapnya, belalang goreng/bacem.(4)Harga oleh-oleh gunung Kidul sangat relatif murah.

\section{Daftar Rujukan}

Ariani, R. (1994). Studi Kelayakan Seni Kuliner Bali Mengenai Hidangan Tradisional Provinsi Bali. Laporan Penelitian. Singaraja: STKIP.

Baiquni, M. (2004). Buku Ajar Manajemen Strategis. Program Studi Kajian Pariwisata Sekolah Pascasarjana. Yogyakarta. Universitas Gadjah Mada.

Buchari, A. (2000). Manajemen Pemasaran dan Pemasaran Jasa. Alfabeta, Bandung

Disparta. (2007a). Brosur: Pesona Di Ujung Tenggara Gunungkidul. Wonosari:Dinas Pariwisata dan Kebudayaan Gunung Kidul. 
Disparta. (2007b). Buku: Data Potensi Kepariwisatan Dan Kebudayaan Kabupaten Gunung Kidul. Wonosari. Dinas Pariwisata dan Kebudayaan Gunung Kidul.

Disparta. (2007c) Leafleat: Mutiara Wisata dan Budaya. Wonosari: Dinas Pariwisata dan Kebudayaan Gunung Kidul.

Disparta. (2007d). Leafleat: Welcome to Gunungkidul. Wonosari: Dinas, Pariwisata dan Kebudayaan Gunung Kidul.

Marpaung. 2002. Pengetahuan Kepariwisataan. Bandung: Afabeta.

Marsum, W. A. (2001). Restoran \& Segala Permasalahannya. Yogyakarta: Andi.

Musanef. 1996. Manajemen Usaha Pariwisata di Indonesia. Jakarta: PT Agung.

Suriani, N. M. (2009). Seni Kuliner Bali sebagai Salah Satu Daya Tarik Wisata Studi Kasus di Warung Babi Guling Ibu Oka di Kelurahan Ubud, Gianyar, Bali. Program Studi Magister S2 Kajian Pariwisata. Universitas Udayana.

Yoeti, O. A. (2006). Pariwisata Budaya: Masalah dan Solusinya. Jakarta: Pradnya Paramita. 